\title{
Coagulopathy in SARS-CoV-2 Infected Patients: Implication for the Management of COVID-19
}

\author{
Sisay Getu (D) \\ Tegenaw Tiruneh $\mathbb{D}^{\prime}$ \\ Henok Andualem (iD) ${ }^{2}$ \\ Wasihun Hailemichael (iD) ${ }^{2}$ \\ Teklehayimanot Kiros (D) $^{3}$ \\ Demeke Mesfin Belay (iD ${ }^{4}$ \\ Mulugeta Kiros $\mathbb{D}^{3}$ \\ 'Hematology and Immuno-hematology, \\ Medical Laboratory Science, College of \\ Health Sciences, Debre Tabor University, \\ Debre Tabor, Ethiopia; ${ }^{2}$ Immunology and \\ Molecular Biology, Medical Laboratory \\ Science, College of Health Sciences, \\ Debre Tabor University, Debre Tabor, \\ Ethiopia; ${ }^{3}$ Microbiology, Medical \\ Laboratory Science, College of Health \\ Sciences, Debre Tabor University, Debre \\ Tabor, Ethiopia; ${ }^{4}$ Pediatrics and Child \\ Health Nursing, College of Health \\ Sciences, Debre Tabor University, Debre \\ Tabor, Ethiopia
}

Correspondence: Sisay Getu

Hematology and Immuno-hematology, Medical Laboratory Science, College of Health Sciences, Debre Tabor University, Debre Tabor, Ethiopia

Email sis.gtu@gmail.com

\begin{abstract}
COVID-19 disease has led to an extraordinary inclusive health crisis globally. Elevation of D-dimer is the major remarkable abnormal coagulation test in seriously ill COVID-19 patients. In nearly 50\% of COVID-19 patients, the value of D-dimer was significantly enhancing. Recent literature indicated that COVID-19 patients were at higher risk of developing disseminated intravascular coagulation. Pro-inflammatory cytokines and chemokines are some of the factors leading to these conditions. The majority of COVID-19 patients showed a higher profile of pro-inflammatory cytokines and chemokines in severe clinical conditions. Tumor necrosis factor- $\alpha$ (TNF- $\alpha$ ) and interleukins (ILs) elevated in COVID-19 infected patients. TNF- $\alpha$, IL-6, and IL-1 are major cytokines vital for the inhibition of intrinsic anticoagulant pathways. COVID-19 becomes a higher complication with a significant effect on blood cell production and hemostasis cascades. Deep vein thrombosis and arterial thrombosis are common complications. Changes in hematological parameters are also frequently observed in COVID-19 patients. Especially, thrombocytopenia is an indicator for poor prognosis of the disease and is highly expected and aggravates the likelihood of death of SARS-CoV-2 infected individuals. Thrombopoiesis reduction in COVID-19 patients might be due to viral abuse of the bone marrow/the viral load may affect thrombopoietin production and function. In other ways, immune-inflammationmediated destruction and increased consumption of platelets are also the possible proposed mechanisms for thrombocytopenia. Therefore, the counting of platelet cells is an easily accessible biomarker for disease monitoring. All SARS-CoV-2 infected patients should be admitted and identifying potential higher-risk patients. It is also obligatory to provide appropriate treatments with intensive care and strict follow-up. In addition, considerations of chronic diseases are essential for better prognosis and recovery. The current review discusses coagulopathy among SARS-CoV-2 infected individuals and its complication for the management of the disease.
\end{abstract}

Keywords: COVID-19, SARS-CoV-2, coagulopathy, DIC

\section{Introduction}

There are various genera of coronaviruses. However, only seven viruses have been identified that could infect humans. Among these viruses, the human coronavirus (HCoV)-229E, HCoV-OC43, HCoV-NL63, and HCoV-HKU1 are the primary causes of common cold, while the other three (severe acute respiratory syndrome (SARS)-CoV, Middle East respiratory syndrome (MERS)-CoV and SARS-CoV-2) are known to cause atypical pneumonia. ${ }^{1}$ Nowadays, we are in the era of the recently emerged coronavirus called Severe Acute Respiratory Syndrome corona virus-2 (SARS-CoV-2). SARS-CoV-2 is an enveloped coronavirus with a spherical 
shape that belongs to the genus similar to SARS-CoV and MERS-CoV known as $\beta$-coronavirus though there is a minuscule difference in genetic sequence. ${ }^{1,2}$ It is the etiologic agent of coronavirus disease 2019 (COVID-19), which was initially appeared in China, Wuhan by December 2019. The disease is still continued as a global concern and greatly impacts humanity's culture and economy. ${ }^{3,4}$

Physiologic hemostasis is an intensive process of retaining blood fluid in the circulation either in normal or abnormal conditions. ${ }^{5}$ When blood vessel damages or an injury occurs, a clot is produced to stop bleeding and then localized thrombus formation at the site of the break-in vascular integrity. This is followed by fibrinolysis that dissolves the clot and thereby healing the wound. ${ }^{6}$ Whenever there are imbalance hemostasis cascades, excessive clot formation, or thrombosis might have occurred. The imbalance can also lead to bleeding as a result of excessive fibrinolysis. It is therefore essential to understand the hemostasis systems such as blood vessels, platelets, and plasma proteins to manage diseases related to hemostasis. $^{5}$

In patients with severe COVID-19 disease, the involvement of fibrin deposition has been reported. The severe manifestation is usually characterized by acute respiratory distress syndrome (ARDS); a lung inflammation that leads to an insufficient oxygen supply that could involve multiorgan failure and consecutive death. ${ }^{7}$ Fibrin formation is steadily seen in lung parenchyma cells of ARDS patients. Fibrin accumulation supports the thickening of the hyaline membrane that further promotes the accumulation of fibrin in the alveoli and thus provokes respiratory dysfunction. ${ }^{8-}$

12 In the majority of COVID-19 patients with severe coagulation abnormalities, such as disseminated intravascular coagulation (DIC) and thrombotic microangiopathy, unrecognized thromboembolic complications and a higher risk of death could be occurred in some conditions. ${ }^{13-16}$

\section{Method}

In this review, the data were retrieved from electronic databases, such as PubMed, Google, and Google Scholar. Articles conducted with the aim of coagulopathy in SARSCoV-2 infected patients and its complications for the management of COVID-19 have been included through searching using key terms "coagulopathy, COVID-19, SARS-CoV-2 infected patients, SARS-CoV-2, and COVID-19 complication" separately and in combination. The full-text articles were first to read for eligibility (relevance for the topic), and those which are relevant were included in this review. Articles from a systematic review and meta-analysis have been also used while writing this document. All references were cited using Endnote X8 referencing manager. Most of the articles used in this review were published within this year (2020). However, articles not open accessed and published in languages other than English were not included in this review.

\section{Coagulation Abnormalities in COVID-19 Patients}

Several studies indicated that COVID-19 patients had higher production of pro-inflammatory cytokines and chemokines. Tumor necrosis factor- $\alpha$ (TNF- $\alpha)$, interleukin-6 ((IL-6), and IL-1 are the key cytokines that vigorously inhibit the intrinsic anticoagulation pathways. IL-6 promotes tissue factor expression on lymphocytes, monocytes, and macrophages that consequently recruits coagulation activation and thrombin formation. On the other side, they are also related to the significant initiation of the fibrinolytic system. In addition to the cytokines, the inflammations associated with COVID-19 have been reported to induce the higher production of fibrinolytic factors, such as urokinase-type and plasminogen. This indicates there is active fibrinolysis and waning clotting. This is corroborated by a finding that showed a higher level of D-dimers, a fibrin degradation product; in seriously ill COVID-19 patients. $^{17-19}$ Further on, in some infected patients, the endothelial cell in the alveoli initiates the release of tissue factor (TF) on surfaces of leukocytes and endorses fibrin deposition. On top of that, there is an elevation of plasminogen activator inhibitor 1 (PAI-1), indicating the association of COVID-19 disease with the hypofibrinolytic state. Together, it seems shreds of evidence are equivocal on whether COVID-19 is related to hypo fibrinolysis or hyper-fibrinolysis conditions. $^{20,21}$

Studies indicated that patients with COVID-19 showed leukocytosis, thrombocytopenia, a higher concentration of partial thromboplastin time (PTT), APTT, fibrinogen degradation products (FDPs), and lower levels of antithrombin activity. ${ }^{22,23}$ In addition to this, a study from China revealed that the presence of markedly elevated values of von Willebrand factor (VWF) antigen, VWF activity, and factor VIII. ${ }^{24}$ At the last stages of the disease, 
patients are at higher risk of developing venous thromboembolism (VTE) and DIC. ${ }^{25}$

\section{Complications of Coagulation Disorder Associated with COVID-I 9}

As discussed above, it is reasonable to assume that SARS$\mathrm{CoV}-2$ infection has a considerable effect on hemostasis and blood cell production when the disease progression is becoming worse. Thrombocytopenia and DIC are common complications in seriously ill patients.

\section{Thrombocytopenia in Patients with COVID-I 9}

Changes in hematological parameters are frequently seen in COVID-19 patients, for example thrombocytopenia, which is usually related to poor prognosis of the disease and even death. ${ }^{26} \mathrm{~A}$ recent study done in China showed that COVID-19 patients demonstrated a reduction in platelet cells. Thus is correlated with an increased risk of mortality. ${ }^{27}$ The reduction of platelet cells was more prominent in patients with more severe cases than in mild cases. ${ }^{28}$ Therefore, the counting of platelets cells could be a biomarker for monitoring the disease progression. ${ }^{29-31}$ Platelet count reduction and thrombocytopenia may occur after sepsis, DIC, or drug-induced in most other cases. However, in COVID-19 patients might also occur due to an immune disorder, immune thrombocytopenia (ITP). ITP is an intermittent autoimmune disorder with the feature of platelet count lower than $100 \times 109 / \mathrm{L}$, resulting in an imbalance of blood hemostasis and leading to the risk of bleeding. ${ }^{32-35}$ The other study indicated that $36 \%$ of hospitalized COVID-19 patients could develop thrombocytopenia. $^{3}$

\section{Mechanisms of Thrombocytopenia in COVID-19 Patients}

The mechanisms behind thrombocytopenia in COVID-19 patients can be explained in various means. Platelets recognized SARS-CoV-2 via the surface of toll-like receptors, integrins, and P-selectin. ${ }^{36}$ SARS-CoV-2 may reduce platelet production by the direct impact of the virus on hematopoiesis, megakaryocyte maturation, the elevation of platelet adhesion, and activation. Platelet production could be also reduced because either viral abuse to the bone marrow or the viral load may affect thrombopoietin production and function. Finally, the large consumption of platelets to heal the damaged tissue leading to thrombocytopenia. ${ }^{37}$ The pooled results of nine studies conducted in China, Wuhan among 1779 COVID-19 patients showed low platelets in severe cases. ${ }^{38,39}$ Thrombocytopenia could also have occurred after heparin therapy, known as heparin-induced thrombocytopenia (HIT). ${ }^{28,40-42}$

Heparin-induced thrombocytopenia appears when platelet factor 4 (PF4) that discharges from activated platelets binds to heparin. Subsequently, antibodies are produced against this complex (heparin-PF4). In the next step, the three complexes (antibody-PF4-heparin) bind to platelets via the FcyIIa receptor, this complex further stimulates platelet activation and aggregation. This induces coagulation pathways and subsequent reduction of circulating platelets which finally leading to thrombocytopenia. ${ }^{43,44}$ A higher dose of heparin to treat COVID-19 patients could provoke thrombocytopenia and leads to death. Therefore, other optional anticoagulants should be used to treat critical COVID-19 patients. $^{41}$ Another study indicated that $71.4 \%$ of the patients infected with SARS-CoV-2 develop thrombosis and DIC leading to higher platelet consumption with fatal outcomes. In other mechanisms, SARS-CoV-2 infection could also lead to alveolar damage that captures megakaryocytes and delays the release of platelets from it to the circulation after maturation. ${ }^{45,46}$

Generally, thrombocytopenia in COVID-19 patients is primarily associated with either immune-mediation ${ }^{47}$ or reduction of platelet production (thrombopoiesis) ${ }^{48,49}$ because of the direct influence of the virus on hematopoietic tissue ${ }^{50-52}$ higher platelet consumption ${ }^{53}$ due to increased adherence of platelets ${ }^{54}$ on injured endothelial cells $^{55}$ as indicated in the Figure 1.

\section{Disseminated Intravascular Coagulation}

When endothelial cells are injured, the Hageman factor is activated and leading to the initiation of the intrinsic clotting system. Extrinsic clotting system activation is continued after tissue injury. In the next step, coagulant phospholipids are released from injured cells, such as platelets and red blood cells. The final shared product for these two processes is thrombin production that cleaves fibrinogen and activates factor XIII. Next to this, the fibrinolysis system is produced by the release and aggregation of platelets. In the final stages of the cascade, FDPs are formed through plasmin which contributes to the 


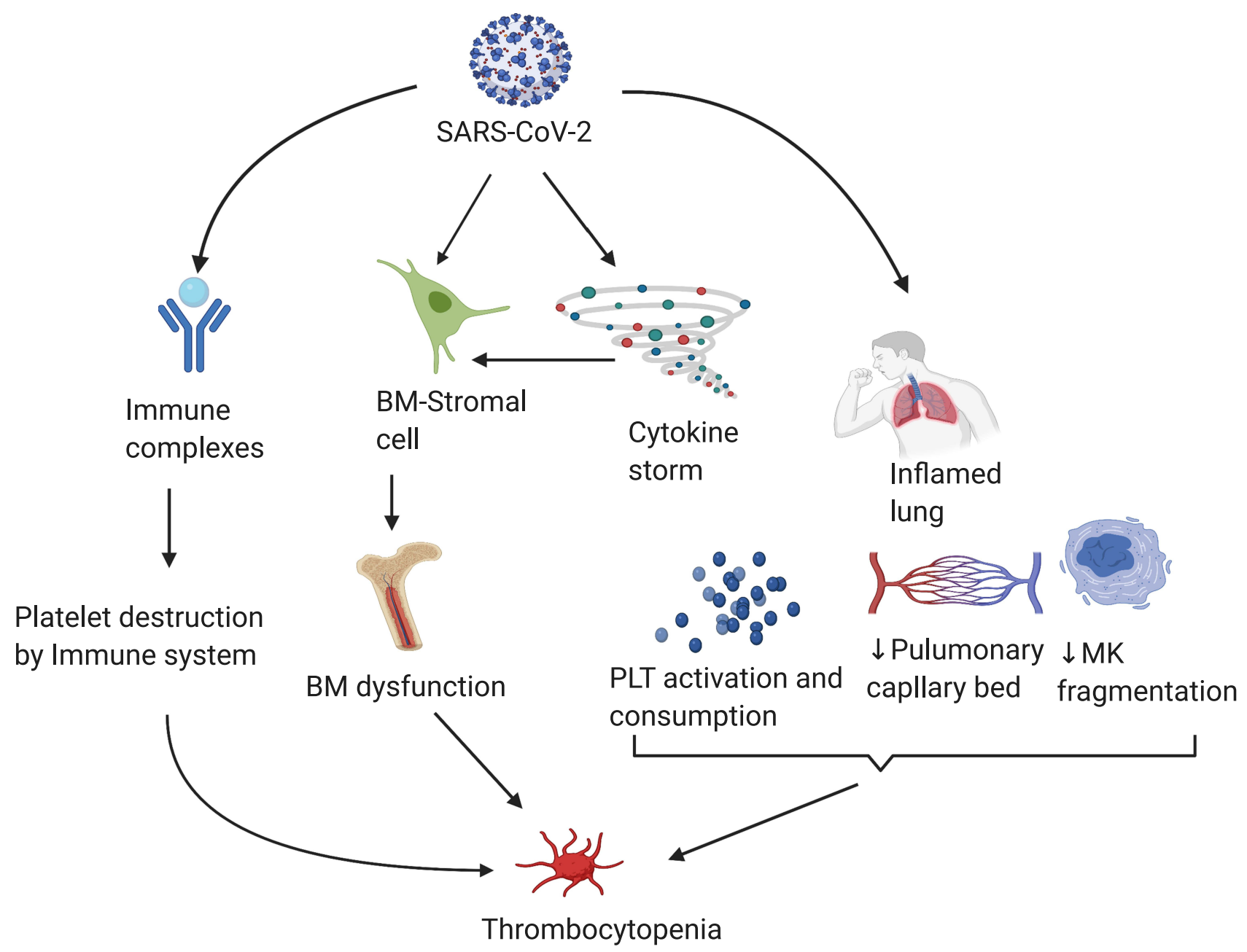

Figure I Mechanisms of thrombocytopenia in COVID-19 patients.

Notes: Bone marrow stromal cells may be infected either directly by the virus or higher cytokine storm because of infection may distract the cell. Thus, in turn leads to bone marrow dysfunction and finally thrombocytopenia can occur. In addition, thrombocytopenia in COVID-19 patients might be due to lung inflammation with SARS-CoV-2 infection which leads to platelets activation with higher consumption, reduction of pulmonary capillary bed and megakaryocytes fragmentation. Similarly, thrombocytopenia with SARS-CoV-2 infection could occur after antigen and antibody complexes formation to protect against the virus results to platelets distraction by the immune system. The figure is created with BioRender; https://app.biorender.com Abbreviations: PLT, platelets; MK, mega kayrocytes, BM; bone marrow.

hemorrhagic diathesis which is the hall marker in the diagnosis of DIC. ${ }^{56}$

In systemic infections, coagulation cascades are triggered and resulting in DIC when the disease is highly complicated. However, in subclinical conditions, DIC occurs as a result of increment in thrombin and fibrin generation. ${ }^{57}$ DIC was firstly found among blood cancer patients though it is also seen in intensive care units (ICU) COVID-19 patients and results in severe bleeding and organ failure nowadays. ${ }^{32,58-61}$ The study conducted by Lodigiani $\mathrm{C}$ et al, showed that development of VTE in ICU COVID-19 patients. ${ }^{62}$ COVID-19 patients that developed DIC showed that thrombocytopenia, elevated D-dimer, decreased factors, such as II, V, VII, and X, lower levels of plasma concentrations of antithrombin and protein C. ${ }^{63-65}$ Similarly, endothelial and mononuclear cells are induced by proinflammatory cytokine. Thus, tissue factor stimulation and unregulated thrombin generation could have occurred after a while. ${ }^{66}$

\section{Thrombotic Microangiopathy}

Thrombotic microangiopathy (TMA) is one the hemolytic anemia that occurs after increment of platelets activation, aggregation, and adhesion to the veins, capillaries, and small arteries walls. TMA is the causes of thrombocytopenia due to higher consumption of platelets. It also causes organ damage, such as renal insufficiency, neurological disease and microangiopathic hemolysis as the results of 
microscopic blood clot formation in vascular endothelium. A postmortem tissue examination from COVID-19 patients showed that accumulation and trapping of inflammatory cells particularly neutrophils and deposition of platelet-rich vascular thrombotic in vessels of lungs which is equivalent to pulmonary TMA. ${ }^{67-69}$ However, thrombocytopenic thrombotic purpura (TTP) which is the cause of both thrombocytopenia and intravascular hemolysis is not a clinical manifestation of COVID-19. ${ }^{4}$

In TMA, higher platelet interaction to the vessel wall is observed as a consequence of extreme-large von Willebrand factor multimers (VWFM) stimulation and release from injured endothelial cells. In normal conditions, ADAMTS-13 (a disintegrin and metalloproteinase with a thrombospondin type I motif-13) cleaves the VWFM. In COVID-19 patients ADAMTS-13 concentration was reduced. Therefore, higher concentration of VWFM leads to increased deposition of platelet-richthrombi in the micro vascular area. ${ }^{70,71}$

\section{Pathophysiology of Complement-Mediated TMA}

The activation of complement pathways is a crucial mechanism in the occurrence of TMAs. When the microbes invade the human body, the complement system protects against invaders as part of innate immunity. After initiation of complement pathway activation, stimulation of platelets and endothelial cells, recruitments of immune cells, and blood coagulation are followed. The ultimate goal of the three complement pathways activation (alternative, classical, and lectin) is membrane attack complex constitution on the surface of target cells and vascular fragment deposition. ${ }^{72,73}$ Recent studies suggest that complement-mediated TMAs were leading to thrombosis.

Angiotensin-converting enzyme 2 (ACE2) is highly expressed on podocytes and epithelial cells after SARSCoV-2 infection causes the risk of cardiac damage and multiple organ dysfunction. Additionally, studies on coronaviruses showed that the de-activation of C3 notably mitigates the lung headed to pro-inflammatory cytokines elevation. Either absences of $\mathrm{C} 3$ or a blockage of its activation has a higher contribution to the spread of the virus through inhibition of immune cell activation and recruitment via lungs. ${ }^{74-77}$ A recent study also revealed that SARS-CoV-2's protein binds to a protein of the lectin pathway resulting in complement-mediated inflammatory lung injury. A further study conducted by Magro et al has also recently shown that a broad accumulation of C5b-9, $\mathrm{C} 4 \mathrm{~d}$, and Mannan-binding lectin serine protease 2 in the micro-vessel of lung of severe COVID-19 patients due to extreme activation of alternative and lectin pathway. ${ }^{78-80}$

\section{Coagulation Tests in COVID-I 9}

An increment of D-dimer value is the main remarkable abnormal coagulation test investigated in seriously ill COVID-19 patients. In nearly 50\% of COVID-19 patients, the value of D-dimer is significantly enhanced. Severe COVID-19 patients are at higher risks of death unless they are supplied oxygen with mechanical ventilation. $^{4,17,81,82}$ In addition, thrombocytopenia is the other abnormality in most severe patients. Most COVID19 patients have a platelet count of (100 to 150$) \times 10^{9} / \mathrm{L}$ or lower than this value. ${ }^{3,17,83-85}$ Slight prolongation of the PT, and aPTT were also found in ICU COVID-19 patients. Similarly, the average plasma fibrinogen levels are notably increased in the majority of severe COVID-19 patients because fibrinogen is an acute phase reactant protein. Nevertheless, a reduction of plasma fibrinogen concentration was shown in some patients. Besides, mild decrement of plasma antithrombin and protein $\mathrm{C}$ concentrations are revealed among survived ICU patients. ${ }^{81,86}$

\section{Management of Coagulopathy}

All hospital-admitted COVID-19 patients could develop VTE. Therefore, control measurements should be taken according to the international treatment guidelines for all high-risk COVID-19 patients. Likewise, respiratory distress, pulmonary thromboembolism (PTE), and blood pressure reduction should need strict follow-up. Vitamin $\mathrm{K}$ antagonist medications, such as warfarin causes stroke mostly in VTE patients. Consequently, patients who take this drug should be controlled. ${ }^{87}$ All SARS-CoV-2 infected patients should be admitted for identifying potentially higherrisk patients and provide treatment with intensive care. In severe patients with tissue hypoxia; determinations of coagulation biomarkers levels, for example, PT, INR, platelet count, D-dimers, and plasma fibrinogen concentration are not sufficient for clinical decision. Therefore, complete clinical assessment and molecular test investigations should be also taken into account. However, D-dimer increments by three to four-fold have a guarantee for admission. ${ }^{88,89}$

\section{Conclusion and Future Perspective}

There are no effective therapies for COVID-19. Hence, strict follow-up and consideration of chronic diseases are essential 
for better prognosis and recovery. COVID-19 leads to coagulation abnormalities with multiple complications, such as DIC and TMA. Thrombo-embolic is one of the complications and specific features of severe COVID-19. It is an indicator for severe COVID-19 and helps to create various management strategies to overcome the disease.

Vitamin $\mathrm{K}$ antagonist medications, such as warfarin, and lower molecular weight heparin could not be given to prevent stroke in COVID-19 patients. Anticoagulants other than heparin should use to treat severe cases. Prolonged PT, aPTT, and elevated D-dimer levels in serious COVID-19 patients lead to DIC combined with severe thrombocytopenia could be used as an alert for quick intervention. Hence, upon observation of these abnormalities, quick responses should be given to reduce death prevalence.

Both ambulatory and hospital-admitted COVID-19 patients are highly suspected of VTE and stroke. Therefore, earlier management of cases is recommended along with blood donation. Generally, health professionals should always be alerted for hemorrhagic conditions in critically ill COVID19 patients, and laboratory investigations related to hemorrhagic conditions should be strictly controlled and interpreted.

\section{Abbreviations}

ACE2, Angiotensin-Converting Enzyme 2; ADAMTS-13, A Disintegrin and Metalloproteinase with a Thrombospondin Type I Motif-13; ARDS, Acute Respiratory Distress Syndrome; COVID-19, Coronavirus Disease 2019; CoVs, Coronaviruses; DIC, Disseminated Intravascular Coagulation; FDPs, Fibrinogen Degradation Products; HCoV, Human Coronavirus; HIT, HeparinInduced Thrombocytopenia; ICU, Intensive Care Unit; ILs, Interleukins; ITP, Immune Thrombocytopenia; MAC, Membrane Attack Complex; MERS, Middle East Respiratory Syndrome; PAI-1, Plasminogen Activator Inhibitor 1; PF4, Platelet Factor 4; PT, Prothrombin Time; PTE, Pulmonary Thromboembolism; PTT, Partial Thromboplastin Time; SARS-CoV-2, Severe Acute Respiratory Syndrome 2; TF, Tissue Factor; TMA, Thrombotic Microangiopathy; TNF- $\alpha$, Tumor Necrosis Factor- $\alpha$; T-PA, Tissue-type Plasminogen Activator; TTP, Thrombocytopenic Thrombotic Purpura; VTE, Venous Thromboembolism; VWF, Von Willebrand Factor; VWFM, Von Willebrand Factor Multimers.

\section{Author Contributions}

All authors made a significant contribution to the work reported in the current review, whether in the conception, or in all these areas; took part in drafting, revising or critically reviewing the article; gave final approval of the version to be published; have agreed on the journal to which the article has been submitted; and agree to be accountable for all aspects of the work.

\section{Funding}

The authors received no specific funding for this work.

\section{Disclosure}

The authors declared no conflicts of interest for this work.

\section{References}

1. Chen Z, Zhang W, Lu Y, et al. From SARS-CoV to Wuhan 2019$\mathrm{CoV}$ outbreak: similarity of early epidemic and prediction of future trends. Cell-Host-Microbe. 2020;D-20-00063.

2. Lancet T. Emerging understandings of 2019-nCoV. Lancet. 2020;395 (10221):311. doi:10.1016/S0140-6736(20)30186-0

3. Guan W-J, Ni Z-Y, Hu Y, et al. Clinical characteristics of coronavirus disease 2019 in China. N Engl J Med. 2020;382(18):1708-1720. doi:10.1056/NEJMoa2002032

4. Zhou F, Yu T, Du R, et al. Clinical course and risk factors for mortality of adult inpatients with COVID-19 in Wuhan, China: a retrospective cohort study. The lancet. 2020;395 (10229):1054-1062. doi:10.1016/S0140-6736(20)30566-3

5. Hokland P. Hematology: Clinical Principles and Applications. 2011.

6. Meduri GU, Annane D, Chrousos GP, Marik PE, Sinclair SE. Activation and regulation of systemic inflammation in ARDS: rationale for prolonged glucocorticoid therapy. Chest. 2009;136 (6):1631-1643. doi:10.1378/chest.08-2408

7. Rocco P, Dos Santos C, Pelosi P. Lung parenchyma remodeling in acute respiratory distress syndrome. Minerva Anestesiol. 2009;75 (12):730-740.

8. Bertozzi P, Astedt B, Zenzius L, et al. Depressed bronchoalveolar urokinase activity in patients with adult respiratory distress syndrome. $N$ Engl J Med. 1990;322(13):890-897. doi:10.1056/ NEJM199003293221304

9. Ware LB, Matthay MA, Parsons PE, Thompson BT, Januzzi JL, Eisner MD. Pathogenetic and prognostic significance of altered coagulation and fibrinolysis in acute lung injury/acute respiratory distress syndrome. Crit Care Med. 2007;35(8):1821.

10. Ham W, Schoonhoven L, Schuurmans MJ, Leenen LP. Pressure ulcers from spinal immobilization in trauma patients: a systematic review. J Trauma Acute Care Surg. 2014;76(4):1131-1141. doi:10.1097/TA.0000000000000153

11. Laterre $\mathrm{P}$, Wittebole X, Jf D. Anticoagulant therapy in acute lung injury. Crit Care Med. 2003;31:S329-S36.

12. Ware LB, Camerer E, Welty-Wolf K, Schultz MJ, Matthay MA. Bench to bedside: targeting coagulation and fibrinolysis in acute lung injury. Am J Physio Lung Cellular Mol Physiol. 2006;291(3): L307-L11. doi:10.1152/ajplung.00157.2006

13. Levi M, Scully M. How I treat disseminated intravascular coagulation. Blood J Am Soc Hematol. 2018;131(8):845-854.

14. Oudkerk M, Büller HR, Kuijpers D, et al. Diagnosis, prevention, and treatment of thromboembolic complications in COVID-19: report of the National Institute for Public Health of the Netherlands. Radiology. 2020;201629.

15. Tang N, Bai H, Chen X, Gong J, Li D, Sun Z. Anticoagulant treatment is associated with decreased mortality in severe coronavirus disease 2019 patients with coagulopathy. J Thrombosis Haemostasis. 2020;18(5):1094-1099. doi:10.1111/jth.14817 
16. Thachil J, Tang N, Gando S, et al. ISTH interim guidance on recognition and management of coagulopathy in COVID-19. J Thrombosis Haemostasis. 2020;18(5):1023-1026. doi:10.1111/ jth. 14810

17. Huang C, Wang Y, Li X, et al. Clinical features of patients infected with 2019 novel coronavirus in Wuhan, China. The Lancet. 2020;395 (10223):497-506. doi:10.1016/S0140-6736(20)30183-5

18. Mehta P, McAuley DF, Brown M, et al. COVID-19: consider cytokine storm syndromes and immunosuppression. Lancet. 2020;395 (10229):1033. doi:10.1016/S0140-6736(20)30628-0

19. Klok F, Kruip M, Van der Meer N, et al. Incidence of thrombotic complications in critically ill ICU patients with COVID-19. Thromb Res. 2020.

20. Al-Samkari H, Karp Leaf RS, Dzik WH, et al. COVID and Coagulation: bleeding and Thrombotic Manifestations of SARS-CoV2 Infection. Blood. 2020;136(4):489-500. doi:10.1182/ blood.2020006520

21. Whyte CS, Morrow GB, Mitchell JL, Chowdary P, Mutch NJ. Fibrinolytic abnormalities in acute respiratory distress syndrome (ARDS) and versatility of thrombolytic drugs to treat COVID-19. J Thrombosis Haemostasis. 2020;18(7):1548-1555. doi:10.1111/ jth. 14872

22. Zhang Y, Xiao M, Zhang S, et al. Coagulopathy and antiphospholipid antibodies in patients with Covid-19. N Engl J Med. 2020;382(17): e38. doi:10.1056/NEJMc2007575

23. Pavoni V, Gianesello L, Pazzi M, Stera C, Meconi T, Frigieri FC. Evaluation of coagulation function by rotation thromboelastometry in critically ill patients with severe COVID-19 pneumonia. $J$ Thromb Thrombolysis. 2020;1.

24. Leonard-Lorant I, Delabranche X, Severac F, et al. Acute pulmonary embolism in COVID-19 patients on CT angiography and relationship to D-dimer levels. Radiology. 2020;201561.

25. Pavoni V, Gianesello L, Pazzi M, Stera C, Meconi T, Frigieri FC. Evaluation of coagulation function by rotation thromboelastometry in critically ill patients with severe COVID-19 pneumonia. J Thromb Thrombolysis. 2020;50::281-6. doi:10.1007/s11239-020-02130-7

26. Chen N, Zhou M, Dong X, et al. Epidemiological and clinical characteristics of 99 cases of 2019322 novel coronavirus pneumonia in Wuhan, China: a descriptive study. Lancet. 2020;395::507-323. doi:10.1016/S0140-6736(20)30211-7

27. Yang X, Yang Q, Wang Y, et al. Thrombocytopenia and its association with mortality in patients with COVID-19. J Thrombosis Haemostasis. 2020;18(6):1469-1472. doi:10.1111/jth.14848

28. Lippi G, Plebani M, Henry BM. Thrombocytopenia is associated with severe coronavirus disease 2019 (COVID-19) infections: a meta-analysis. Clinica Chimica Acta. 2020.

29. Hui P, Cook DJ, Lim W, Fraser GA, Arnold DM. The frequency and clinical significance of thrombocytopenia complicating critical illness: a systematic review. Chest. 2011;139(2):271-278. doi:10.1378/chest.10-2243

30. Raju NA, Rao SV, Joel JC, et al. Predictive value of serum myoglobin and creatine phosphokinase for development of acute kidney injury in traumatic rhabdomyolysis. Indian journal of critical care medicine: peer-reviewed, official publication of. Ind Soc Crit Care Med. 2017;21(12):852. doi:10.4103/ijccm.IJCCM_186_17

31. Vanderschueren S, De Weerdt A, Malbrain M, et al. Thrombocytopenia and prognosis in intensive care. Crit Care Med. 2000;28(6):1871-1876. doi:10.1097/00003246-200006000-00031

32. Gralnick HR, Bagley J, Abrell E. Heparin treatment for the hemorrhagic diathesis of acute promyelocytic leukemia. Am J Med. 1972;52 (2):167-174. doi:10.1016/0002-9343(72)90066-6

33. Zulfiqar -A-A, Lorenzo-Villalba N, Hassler P, Andrès E. Immune thrombocytopenic purpura in a patient with Covid-19. $N$ Engl $J$ Med. 2020;382(18):e43. doi:10.1056/NEJMc2010472

34. Cooper N, Ghanima W. Immune thrombocytopenia. $N$ Engl J Med. 2019;381(10):945-955. doi:10.1056/NEJMcp1810479
35. Swinkels M, Rijkers M, Voorberg J, Vidarsson G, Leebeek FW, Jansen A. Emerging concepts in immune thrombocytopenia. Front Immunol. 2018;9:880. doi:10.3389/fimmu.2018.00880

36. Page MJ, Pretorius E, editors. A Champion of Host Defense: A Generic Large-Scale Cause for Platelet Dysfunction and Depletion in Infection. Seminars in Thrombosis and Hemostasis. Thieme Medical Publishers; 2020.

37. Yang M, Ng MH, Li CK. Thrombocytopenia in patients with severe acute respiratory syndrome. Hematology. 2005;10(2):101-105. doi:10.1080/10245330400026170

38. Kolb-Mäurer A, Goebel W. Susceptibility of hematopoietic stem cells to pathogens: role in virus/bacteria tropism and pathogenesis. FEMS Microbiol Lett. 2003;226(2):203-207. doi:10.1016/S0378-1097(03) 00643-8

39. Alexander T, Thomson VS, Malviya A, Mohan B, Wander GS, et al. Guidance for health care providers on management of cardiovascular complications in patients suspected or confirmed with COVID 19 virus infection. $J$ Assoc Phys India. 2020;68:46.

40. Kravitz MS, Shoenfeld Y. Thrombocytopenic conditions-autoimmunity and hypercoagulability: commonalities and differences in ITP, TTP, HIT, and APS. Am J Hematol. 2005;80(3):232-242. doi:10.1002/ajh.20408

41. Liu X, Zhang X, Xiao Y, et al. Heparin-induced thrombocytopenia is associated with a high risk of mortality in critical COVID-19 patients receiving heparin-involved treatment. medRxiv. 2020.

42. Warkentin TE, Aird WC, Rand JH. Platelet-endothelial interactions: sepsis, HIT, and antiphospholipid syndrome. ASH Educ Prog Book. 2003;2003(1):497-519.

43. Rauova L, Zhai L, Kowalska MA, Arepally GM, Cines DB, Poncz M. Role of platelet surface PF4 antigenic complexes in heparin-induced thrombocytopenia pathogenesis: diagnostic and therapeutic implications. Blood. 2006;107(6):2346-2353. doi:10.1182/ blood-2005-08-3122

44. Warkentin TE, Levine MN, Hirsh J, et al. Heparin-induced thrombocytopenia in patients treated with low-molecular-weight heparin or unfractionated heparin. $N$ Engl J Med. 1995;332(20):1330-1336. doi:10.1056/NEJM199505183322003

45. Arachchillage DR, Laffan M. Abnormal coagulation parameters are associated with poor prognosis in patients with novel coronavirus pneumonia. J Thrombosis Haemostasis. 2020;18(5):1233-1234. doi:10.1111/jth. 14820

46. Mandal RV, Mark EJ, Kradin RL. Megakaryocytes and platelet homeostasis in diffuse alveolar damage. Exp Mol Pathol. 2007;83 (3):327-331. doi:10.1016/j.yexmp.2007.08.005

47. Nicholson AC, Hajjar DP. Herpesviruses in atherosclerosis and thrombosis: etiologic agents or ubiquitous bystanders? Arterioscler Thromb Vasc Biol. 1998;18(3):339-348. doi:10.1161/01. ATV.18.3.339

48. Bierman H, Nelson E. Hematodepressive virus diseases of Thailand. Ann Intern Med. 1965;62(5):867-884. doi:10.7326/0003-4819-62$5-867$

49. Nakao S, Lai C-J, Young NS Dengue virus, a flavivirus, propagates in human bone marrow progenitors and hematopoietic cell lines. 1989.

50. Halstead SB. Antibody, macrophages, dengue virus infection, shock, and hemorrhage: a pathogenetic cascade. Rev Infect Dis. 1989;11 (Supplement_4):S830-S9. doi:10.1093/clinids/11.Supplement_4. S830

51. Terada H, Baldini M, Ebbe S, Madoff M. Interaction of influenza virus with blood platelets. Blood. 1966;28(2):213-228. doi:10.1182/ blood.V28.2.213.213

52. Kabra S, Jain Y, Singhal T, Ratageri V. Dengue hemorrhagic fever: clinical manifestations and management. Indian $J$ Pediatrics. 1999;66(1):93. doi:10.1007/BF02752362

53. Kapdi M, Shah I. Dengue and haemophagocytic lymphohistiocytosis. Scand J Infect Dis. 2012;44(9):708-709. doi:10.3109/ 00365548.2011.652667 
54. Curwen K, Gimbrone JM, Handin R. In vitro studies of thromboresistance: the role of prostacyclin (PGI2) in platelet adhesion to cultured normal and virally transformed human vascular endothelial cells. Laboratory investigation. $j$ Technical Methodspathol. 1980;42 (3):366-374.

55. Stemerman MB. Vascular intimal components: precursors of thrombosis. Prog Hemost Thromb. 1974;2:1.

56. Colman RW, Robboy SJ, Minna JD. Disseminated intravascular coagulation (DIC): an approach. Am J Med. 1972;52(5):679-689. doi:10.1016/0002-9343(72)90058-7

57. Levi M, Levi M, Ten Cate H, van der Poll T, Sj VD. Pathogenesis of disseminated intravascular coagulation in sepsis. JAMA. 1993;270 (8):975-979. doi:10.1001/jama.1993.03510080079035

58. Müller-Berghaus G, Ten Cate H, Levi M. Disseminated intravascular coagulation: clinical spectrum and established as well as new diagnostic approaches. Thromb Haemost. 1999;82(08):706-712. doi:10.1055/s-0037-1615900

59. Ten Cate H, Timmerman JJ, Levi M. The pathophysiology of disseminated intravascular coagulation. Thromb Haemost. 1999;82 (08):713-717. doi:10.1055/s-0037-1615901

60. Levi M, Ten Cate H. Disseminated intravascular coagulation. $N$ Engl J Med. 1999;341(8):586-592. doi:10.1056/NEJM199908193410807

61. Rosenthal RL. Acute promyelocytic leukemia associated with hypofibrinogenemia. Blood. 1963;21(4):495-508. doi:10.1182/blood. V21.4.495.495

62. Lodigiani C, Iapichino G, Carenzo L, et al. Venous and arterial thromboembolic complications in COVID-19 patients admitted to an academic hospital in Milan, Italy. Thromb Res. 2020;191:9-14. doi:10.1016/j.thromres.2020.04.024

63. Delabranche X, Stiel L, Severac F, et al. Evidence of netosis in septic shock-induced disseminated intravascular coagulation. Shock: injury, Inflammation, and Sepsis. Lab Clin Approaches. 2017;47 (3):313-317.

64. Levi M, editor. Platelets in Critical Illness. Seminars in Thrombosis and Hemostasis. Thieme Medical Publishers; 2016.

65. Valerio L, Head RN. Neck, and Abdominopelvic Septic Thrombophlebitis: current Evidence and Challenges in Diagnosis and Treatment. Hämostaseologie. 2020;40(03):301-310. doi:10.1055/a-1177-5127

66. Levi M, Van der Poll T, Büller HR. Bidirectional relation between inflammation and coagulation. Circulation. 2004;109(22):2698-2704. doi:10.1161/01.CIR.0000131660.51520.9A

67. Scully M, How GT. I treat thrombotic thrombocytopenic purpura and atypical haemolytic uraemic syndrome. Br J Haematol. 2014;164 (6):759-766. doi:10.1111/bjh.12718

68. Fox SE, Akmatbekov A, Harbert JL, Li G, Brown JQ, Vander Heide RS. Pulmonary and cardiac pathology in African American patients with COVID-19: an autopsy series from New Orleans. Lancet Respir Med. 2020;8(7):681-686. doi:10.1016/S22132600(20)30243-5

69. Ruggenenti P, Noris M, Remuzzi G. Thrombotic microangiopathy, hemolytic uremic syndrome, and thrombotic thrombocytopenic purpura. Kidney Int. 2001;60(3):831-846. doi:10.1046/j.15231755.2001.060003831.x

70. Levi M, Scully M, Singer M. The role of ADAMTS-13 in the coagulopathy of sepsis. J Thrombosis Haemostasis. 2018;16 (4):646-651. doi:10.1111/jth.13953

71. Schwameis M, Schörgenhofer C, Assinger A, Steiner MM, Jilma B. Von Willebrand factor excess and ADAMTS13 deficiency: a unifying pathomechanism linking inflammation to thrombosis in DIC, malaria, and TTP. Thromb Haemost. 2015;113(4):708. doi:10.1160/TH14-09-0731

72. Willan J, Aj K, Djebbari F, et al. Assessing the Impact of Lockdown: fresh Challenges for the Care of Haematology Patients in the COVID-19 Pandemic. Br J Haematol. 2020.
73. Peto J. Covid-19 mass testing facilities could end the epidemic rapidly. BMJ. 2020;368.

74. Chen L, Li X, Chen M, Feng Y, The XC. ACE2 expression in human heart indicates new potential mechanism of heart injury among patients infected with SARS-CoV-2. Cardiovasc Res. 2020;116 (6):1097-1100. doi:10.1093/cvr/cvaa078

75. Wan Y, Shang J, Graham R, Baric RS, Li F. Receptor recognition by the novel coronavirus from Wuhan: an analysis based on decade-long structural studies of SARS coronavirus. J Virol. 2020;94:7. doi:10.1128/JVI.00127-20

76. Gralinski L, Sheahan T, Morrison T, et al. Complement activation contributes to severe acute respiratory syndrome coronavirus pathogenesis. mBio. 2018;9:e1753-18. doi:10.1128/mBio.01753-18

77. Jiang Y, Zhao G, Song N, et al. Blockade of the C5a-C5aR axis alleviates lung damage in hDPP4-transgenic mice infected with MERS-CoV. Emerging Microbes Infect. 2018;7(1):1-12.

78. Gao T, Hu M, Zhang $\mathrm{X}$, et al. Highly pathogenic coronavirus $\mathrm{N}$ protein aggravates lung injury by MASP-2-mediated complement over-activation. MedRxiv. 2020.

79. Magro C, Mulvey JJ, Berlin D, et al. Complement associated microvascular injury and thrombosis in the pathogenesis of severe COVID-19 infection: a report of five cases. Trans Res. 2020;220:1-13. doi:10.1016/j.trsl.2020.04.007

80. Abbaszadeh-Goudarzi K, Radbakhsh S, Pourhanifeh MH, et al. Circular RNA and diabetes: epigenetic regulator with diagnostic role. Curr Mol Med. 2020;20(7):516-526. doi:10.2174/ 1566524020666200129142106

81. Tang N, Li D, Wang X, Sun Z. Abnormal coagulation parameters are associated with poor prognosis in patients with novel coronavirus pneumonia. J Thrombosis Haemostasis. 2020;18(4):844-847. doi:10.1111/jth. 14768

82. Henry BM, Benoit SW, Hoehn J, Lippi G, Favaloro EJ, Benoit JL, editors. Circulating plasminogen concentration at admission in patients with coronavirus disease 2019 (COVID-19). In: Seminars in Thrombosis and Hemostasis. Thieme Medical Publishers; 2020.

83. Christensen B, Favaloro EJ, Lippi G, Van Cott EM. Hematology laboratory abnormalities in patients with coronavirus disease 2019 (COVID-19).Semin Thrombosis Hemost. 2020;46(7):845-849.

84. Brogaard Larsen J, Pasalic L, Hvas A. Platelets in coronavirus disease. Semin Thromb Hemost. 2020;46(07):823-825. doi:10.1055/ s-0040-1710006

85. Akca S, Haji-Michael P, De Mendonça A, Suter P, Levi M, Vincent J-L. Time course of platelet counts in critically ill patients. Crit Care Med. 2002;30(4):753-756. doi:10.1097/00003246200204000-00005

86. Henry BM, De Oliveira MHS, Benoit S, Plebani M, Lippi G. Hematologic, biochemical and immune biomarker abnormalities associated with severe illness and mortality in coronavirus disease 2019 (COVID-19): a meta-analysis. Clin Chem Lab Med. 2020;58 (7):1021-1028. doi:10.1515/cclm-2020-0369

87. Obe BH, Retter A, McClintock C. Practical guidance for the prevention of thrombosis and management of coagulopathy and disseminated intravascular coagulation of patients infected with COVID-19. 2020.

88. Akima S, McLintock C, Hunt BJ. RE: ISTH interim guidance to recognition and management of coagulopathy in COVID-19. J Thrombosis Haemostasis. 2020;18(8):2057-2058. doi:10.1111/ jth. 14853

89. Barrett CD, Moore HB, Yaffe MB, Moore EE. ISTH interim guidance on recognition and management of coagulopathy in COVID19. J Thrombosis Haemostasis. 2020;18(8):2060-2063. doi:10.1111/ jth. 14860 


\section{Publish your work in this journal}

The Journal of Blood Medicine is an international, peer-reviewed open access, online journal publishing laboratory, experimental and clinical aspects of all aspect pertaining to blood based medicine including but not limited to: Transfusion Medicine; Blood collection, Donor issues, Transmittable diseases, and Blood banking logistics; Immunohematology; Artificial and alternative blood based therapeutics; Hematology; Biotechnology/nanotechnology of blood related medicine; Legal aspects of blood medicine; Historical perspectives. The manuscript management system is completely online and includes a very quick and fair peer-review system. Visit http://www.dovepress.com/testimonials.php to read real quotes from published authors. 